\title{
Physical and Chemical Properties of FINEMET-Type Amorphous Alloys
}

\author{
K. ZÁBRANSKÝ AND Y. JIRÁSKOVÁ \\ Institute of Physics of Materials, Academy of Sciences of the Czech Republic \\ Žižkova 22, 61662 Brno, Czech Republic

\begin{abstract}
Influence of composition variations on the physical and chemical properties of rapidly quenched NANOPERM-type, FeNbCuB, and FINEMET-type, $\mathrm{Fe}(\mathrm{Ni}) \mathrm{NbCu}(\mathrm{Si}) \mathrm{B}$, alloys in amorphous states, is investigated by Mössbauer spectroscopy, magnetic and electrochemical methods. While the partial substitution of Si for B leads to weak effects, that of Ni for Fe results in pronounced changes of both magnetic properties and chemical stability.
\end{abstract}

PACS numbers: $75.50 . \mathrm{Kj}, 75.60 . \mathrm{Nt}$

\section{Introduction}

Nanocrystalline alloys attract interest due to their exceptional soft magnetic properties [1] making them useful for numerous technical applications [1, 2]. They can be prepared by various methods either directly in one process, e.g, by mechanical alloying [3], or indirectly through an amorphous precursor with a subsequent controlled heat treatment [2]. The present contribution is focused on one NANOPERM- and two FINEMET-type alloys prepared by the latter method. Our main aim is to get complex view on these alloys; here we summarize results obtained for their as-quenched amorphous states by using a broad spectrum of experimental techniques.

\section{Experimental details}

The planar flow casting was used for production of samples in the form of ribbons approximately $9 \mathrm{~mm}$ wide and $29 \mu \mathrm{m}$ thick with the nominal compositions of $\mathrm{Fe}_{80} \mathrm{Nb}_{3} \mathrm{Cu}_{1} \mathrm{~B}_{16}$ (FM1), $\mathrm{Fe}_{80} \mathrm{Nb}_{3} \mathrm{Cu}_{1} \mathrm{Si}_{6} \mathrm{~B}_{10}$ (FM2), and $\mathrm{Fe}_{33.5} \mathrm{Ni}_{40} \mathrm{Nb}_{3} \mathrm{Cu}_{1} \mathrm{Si}_{13.5} \mathrm{~B}_{9}$ (FM3). The conversion electrons Mössbauer spectroscopy (CEMS) was used to check the amorphous structure of ribbon surfaces $(\approx 300 \mathrm{~nm})$ from both sides while the $\gamma$-ray Mössbauer spectroscopy in transmission geometry was applied for bulk measurements. The ribbon surfaces are visually distinguished. The surface which was in direct contact with cooling wheel is matt and will be denoted by " $\mathrm{m}$ " while the other surface exposed to surrounding atmosphere is shiny and will 
be denoted by "s". The spectra were taken at room temperature (RT) using ${ }^{57} \mathrm{Co} / \mathrm{Rh}$ source and evaluated using CONFIT program package [4]. Velocity scale was calibrated with standard pure $\alpha$-iron foil at RT.

The magnetic measurements were done by a vibrating sample magnetometer. The coercivity and magnetic polarization data were obtained from the RT hysteresis curves $\left(H_{\max }= \pm 1.2 \mathrm{MA} / \mathrm{m}\right)$. The thermomagnetic curves were measured in temperature interval of $(300 \div 1000) \mathrm{K}$ in vacuum using temperature sweep of $4 \mathrm{~K} / \mathrm{s}$ and external field of $4 \mathrm{kA} / \mathrm{m}$.

The corrosion resistance was studied by means of potentio-dynamic polarization measurements. They were performed in $3.5 \% \mathrm{NaCl}$ solution $(\mathrm{pH} 6.5)$ in a $330 \mathrm{ml}$ cell with standard three electrode arrangement (working, $\mathrm{Ag} / \mathrm{AgCl}$ reference and Pt counter electrode). The exposed area was $0.5 \mathrm{~cm}^{2}$. After recording the free corrosion potential for $30 \mathrm{~min}$, the polarization scan was started at $250 \mathrm{mV}$ relative to the free corrosion potential with a scan rate of $0.2 \mathrm{mV} / \mathrm{s}$.

\section{Results and discussion}

The transmission Mössbauer spectra (Fig. 1, bottom) were analyzed using two Gaussian distributions of hyperfine induction, which corresponds to varying local environments of resonating iron atoms in amorphous systems. No traces of crystallization were observed. The hyperfine parameters of amorphous phase are related to the iron near neighbors. The partial substitution of Si for B leads to negligible changes in hyperfine parameters as documented by nearly identical values of the isomer shifts $(I S)$, the quadrupole splittings $(E Q)$ and the mean values of hyperfine induction $\left(B_{\text {mean }}\right)$ for the FM1 and FM2 samples: $I S=0.040 \pm$ $0.001 \mathrm{~mm} / \mathrm{s}, E Q=0.010 \pm 0.001 \mathrm{~mm} / \mathrm{s}, B_{\text {mean }}=21.0 \pm 0.7 \mathrm{~T}$. On the other hand, the partial substitution of $\mathrm{Ni}$ for $\mathrm{Fe}$ (FM3) causes significant changes: $E Q=$ $0.020 \pm 0.002 \mathrm{~mm} / \mathrm{s}, I S=0.164 \pm 0.005 \mathrm{~mm} / \mathrm{s}, B_{\text {mean }}=14.0 \pm 0.5 \mathrm{~T}$, in good agreement, e.g., with Ref. [4]. The same model was used also for evaluation of the CEMS spectra of shiny and matt surfaces of the samples, except for the FM2 sample where discrete sextuplets had to be added for a crystalline bcc-Fe(Si) phase (Fig. 1, top and middle). The presence of the crystalline phase is more pronounced at the shiny surface (Fig. 1, FM2, s).

The results obtained from magnetic measurements are summarized in Table. The transition of amorphous phase from the ferromagnetic into a paramagnetic state occurs below the onset of crystallization for all samples. In analogy to the hyperfine parameters, the Curie temperatures $T_{\mathrm{C}}$ of the FM1 and FM2 samples nearly coincide whereas that of the FM3 sample deviates significantly. This is in good agreement with observations of other authors [5]. The same is also valid for the crystallization temperature $T_{\text {cr }}$ as well as for the saturation and remanent polarization $J_{\mathrm{s}}, J_{\mathrm{r}}$, respectively. Let us note that the trend of $J_{\mathrm{s}}$ corresponds roughly to variations of $B_{\text {mean }}$. On the contrary, the coercivity $H_{\mathrm{c}}$ is fairly sensitive to both substitutions. 


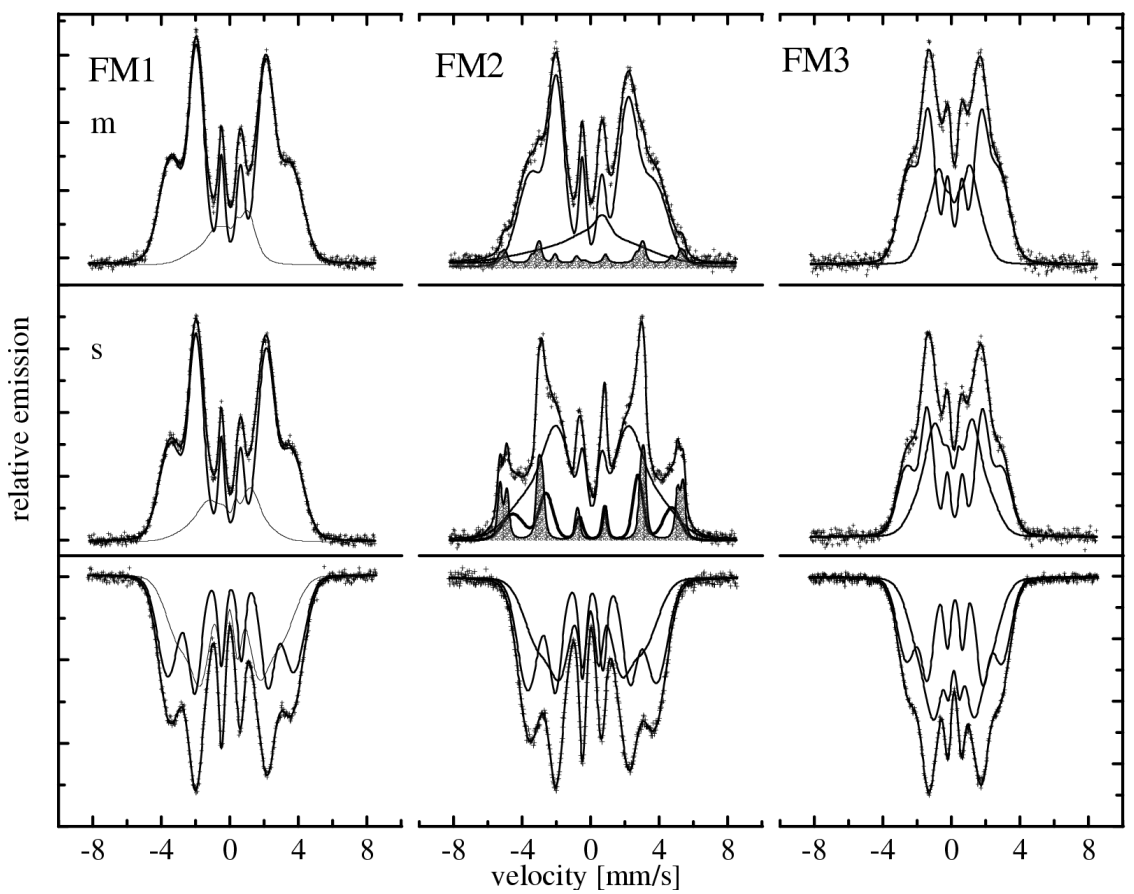

Fig. 1. CEMS spectra of the FM1, FM2, and FM3 samples: matt (m) and shiny (s) surfaces. The bottom parts show the $\gamma$-rays Mössbauer spectra.

TABLE

Properties of the FM1, FM2, and FM3 samples: Curie $\left(T_{\mathrm{C}}\right)$ and crystallization $\left(T_{\mathrm{cr}}\right)$ temperatures, coercivity $\left(H_{\mathrm{c}}\right)$, magnetic polarizations saturated $\left(J_{\mathrm{s}}\right)$ and remanent $\left(J_{\mathrm{r}}\right)$, and corrosion rates on matt $\left(r_{\text {corrm }}\right)$ and shiny $\left(r_{\text {corrs }}\right)$ surfaces.

\begin{tabular}{c|c|c|c|c|c|c|c}
\hline \hline Sample & $\begin{array}{c}T_{\mathrm{C}} \\
{[\mathrm{K}]}\end{array}$ & $\begin{array}{c}T_{\mathrm{cr}} \\
{[\mathrm{K}]}\end{array}$ & $\begin{array}{c}H_{\mathrm{c}} \\
{[\mathrm{kA} / \mathrm{m}]}\end{array}$ & $\begin{array}{c}J_{\mathrm{s}} \\
{[\mathrm{T}]}\end{array}$ & $\begin{array}{c}J_{\mathrm{r}} \\
{[\mathrm{T}]}\end{array}$ & $\begin{array}{c}r_{\text {corrm }} \\
{[\mathrm{mm} / \text { year }]}\end{array}$ & $\begin{array}{c}r_{\text {corrs }} \\
{[\mathrm{mm} / \text { year }]}\end{array}$ \\
\hline FM1 & 530 & 693 & 0.89 & 1.506 & 0.149 & 0.629 & 0.285 \\
FM2 & 528 & 703 & 1.46 & 1.559 & 0.148 & 0.737 & 0.865 \\
FM3 & 404 & 773 & 1.08 & 0.735 & 0.080 & 0.006 & 0.002
\end{tabular}

The electrochemical data (Table) show that Ni alloying (FM3) results in a marked decrease in the corrosion rates and improvement of chemical stability in agreement with cyclic voltammetry experiments [6]. The reactivity of the matt surface is higher as compared to the shiny surface for the FM1 and FM3 samples, whereas the opposite relation is observed for the FM2 sample, most probably owing to the observed surface crystallization (see Fig. 1). This explanation can be correlated with the Mössbauer phase analysis of the FM2 sample which re- 
sulted in a higher degree of crystallization of the shiny surface. The formation of nanocrystals in the amorphous structure contributes to a larger inhomogeneity accompanied by enhanced probability of interphase corrosion.

\section{Conclusions}

The investigations of three FINEMET-type alloys, FM1, FM2, and FM3, in the as-quenched amorphous states have revealed weak influence of the substitution of silicon for boron on the hyperfine parameters, the Curie temperature and the magnetic polarization; the only magnetic property sensitive to this alloying is the coercivity. On the other hand, the substitution of nickel for iron leads to pronounced changes not only in all magnetic parameters but it has also an outstanding effect on electrochemical stability.

\section{Acknowledgments}

The authors thank to Dr. D. Janičkovič (IP, SAS, Bratislava, SK) for supplying the amorphous samples. They acknowledge financial support by the Czech Science Foundation (202/05/2111 and 106/05/H008) and the Academy of Sciences of the Czech Republic (AV0Z20410507).

\section{References}

[1] Y. Youshizawa, S. Oguma, K. Yamauchi, J. Appl. Phys. 64, 6044 (1988).

[2] G. Herzer, IEEE Trans. Magn. MAG-26, 1397 (1990).

[3] E. Fechová, P. Kollár, J. Füzer, J. Kováč, P. Petrovič, V. Kavečanský, Mater. Sci. Eng. B 107, 155 (2004).

[4] T. Žák, Y. Jirásková, Surf. Interf. Anal. 38, 710 (2006).

[5] P. Duhaj, P. Švec, J. Sitek, D. Janičkovič, Mater. Sci. Eng. A 304-306, 178 (2001).

[6] G. Vara, A.R. Pierna, J.A. García, J.A. Jimenez, M. Delamar, J. Non-Cryst. Solids 353, 1008 (2007). 